\title{
A strategy for the innovative low-carbon growth of the Sverdlovsk Region, Russia
}

\author{
V. P. Anufriev \& A. P. Kuligin \\ Ural Federal University, Russia
}

\begin{abstract}
The objective for this project was to work out the practical recommendations for the curb of greenhouse gas (GHG) emission at a regional level.

This work was carried out in the following steps: a survey on GHG emission, the identification of the overall historical and current GHG emission rates as well as a breakdown into economical sectors, the forecast for future GHG emissions (up to 2020), identification of the technological opportunities for GHG emission reduction and an assessment of their potential reduction, identification of the main barriers for low-carbon development and the drafting of proposals and the instruments for GHG reduction.

A draft for the low-carbon strategy was discussed with stakeholders and delivered to the government of Sverdlovsk Oblast.

Keywords: greenhouse gases (GHG) emission, low-carbon strategy, low-carbon development, carbon footprint, energy efficiency.
\end{abstract}

\section{Introduction}

According to the edict of the president of the Russian Federation dated 30.09.2013, No. 752, Russia has to cut greenhouse gases (GHG) emission by $25 \%$ by the year 2020 against the reference year of 1990 . To achieve this target the government is charged with the development of an action plan, which should include a set of sector-wise GHG emission reduction indices.

In spite of this target we are convinced that the task has not been officially delegated at a regional level and that efforts at the level of advanced regions will contribute to the overall achievements.

The Sverdlovsk region is one of the most economically developed and GHG intensive regions in Russia. According to assessments made by the Ural Center for Energy Efficiency and Environment (UCEE) and the Center for Energy 
Efficiency (CENEf), it ranks second in terms of GHG emission. That is why the issues of GHG management are of current concern.

Therefore, the objective of this work was to develop a regional low-carbon strategy and to present it to stakeholders and the local government.

This study uses data and results obtained within the British-Russian project "Creating the Framework for Russian Regional Low Carbon Development", which is supported by the government of the UK (Foreign and Commonwealth Office) and the Ministry of Industry and Science of the Sverdlovsk Region [1].

Work was carried out in the following steps:

1. A survey on GHG emission, identification of the overall historical and current GHG emission rates as well as it breakdown by economical sectors.

2. The forecast of the future (up to 2020) GHG emissions.

3. Identification of the technological opportunities for $\mathrm{GHG}$ emission reduction and the reduction potential assessment.

4. Identification of the main barriers for low-carbon development, drafting of proposals and instruments for the reduction of barriers.

\section{Historical and current GHG emissions}

To determine the actions required for achieving the identified targets it is first necessary to obtain the following information:

- GHG emissions in the reference 1990 year, which is conventionally accepted as a basic year.

- Current GHG emissions and current trends.

- Key categories of GHG emission.

The joint carbon footprint of the Sverdlovsk Region was assessed for the years 1990 and for the period of 2000 to 2009. Special attention was paid to recent emissions and the emissions of the basic year.

The 2006 IPCC Guidelines for National Greenhouse Gas Inventories (Guidelines 2006) were used as a main methodological instrument for emission assessment. The team followed the main principles of GHG inventory declared in the Guidelines of 2006: transparency, completeness, consistency, comparability and accuracy.

The official statistics were used as the main source of information but the data was checked for consistency. Any requests for additional information were made as necessary.

To be confident that the results are correct, the fuel consumption, fuel mix and GHG emission rate for each year were compared to the production rate of the main fuel intensive products and services. The GHG emission rate (carbon footprint) against emission in the basic year $\left(\mathrm{E}_{1990}\right)$ is shown in Figure 1. The earlier results obtained by UCEE in 2001 are also shown. The results for the period of 2001 to 2004 are omitted because of the low reliability of data.

Between the years 1990 and 1999 GHG emission had dropped due to the structural changes in economy. Since $2000 \mathrm{GHG}$ emissions have steadily grown at the rate of about $1.2 \%$ per year and reached $79.5 \%$ of $\mathrm{E}_{1990}$ by 2008 . The decline of emissions in 2009 is stipulated by the financial crisis. 


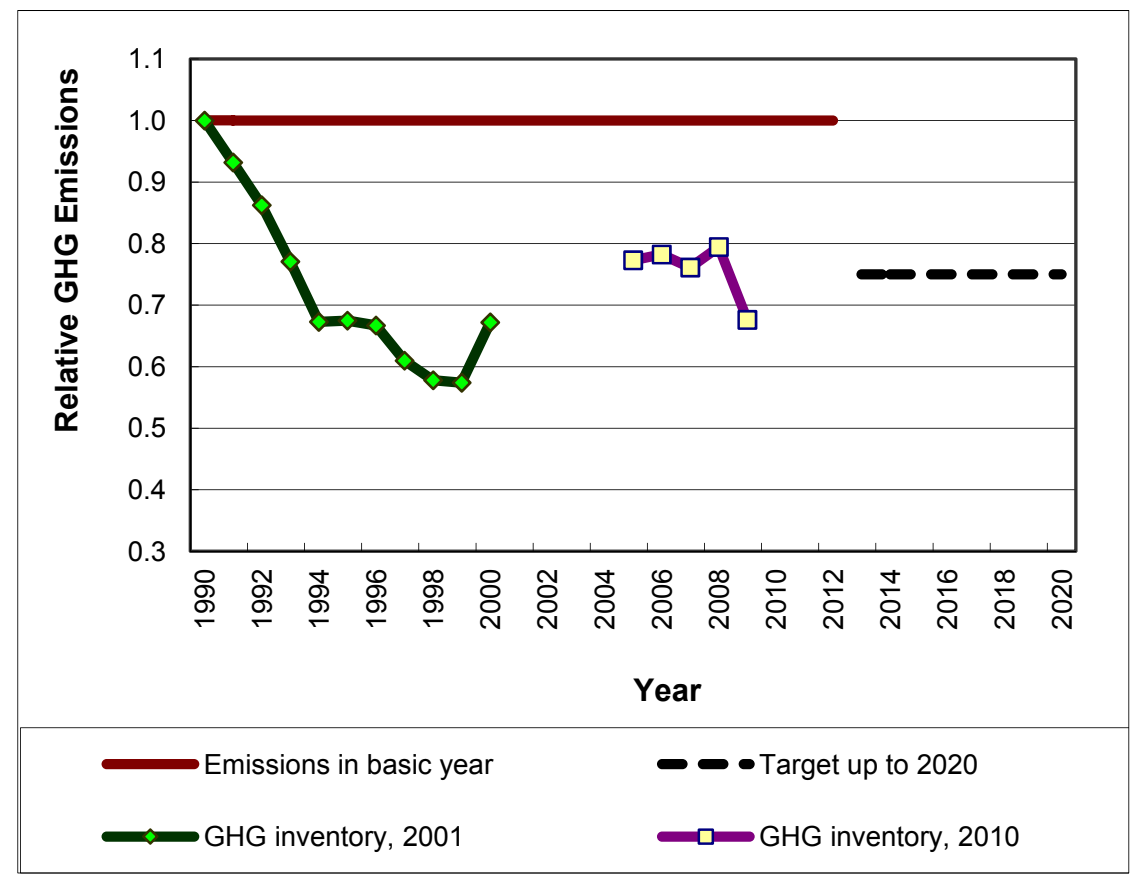

Figure 1: Historical and current GHG emissions in Sverdlovsk Region (Russia).

\section{Forecast}

A forecast of emissions up to 2020 was made for four different scenarios for Sverdlovsk Oblast economical development:

- Business-as-usual;

- Business-as-usual plus implementation of the energy efficiency program of the Sverdlovsk Region (developed by the Institute of Energy Conservation of Sverdlovsk Oblast, INES);

- Innovative scenario (Russian Agency on balances forecast in power sector);

- Scenario declared by the Energy Strategy of Russian Federation and applied in this work to the Sverdlovsk Region.

The results are presented in Figure 2. All the scenarios show the ongoing rate of growth of emissions without any tendency for slowing down.

\section{Opportunities for GHG emission reduction}

To identify the most efficient and cost-effective technical actions it is necessary to know the emissions breakdown over various sectors and sources. This distribution is basically known as the Sverdlovsk Oblast footprint structure. The first GHG Survey that was carried out in 2001 has shown that the sector for 


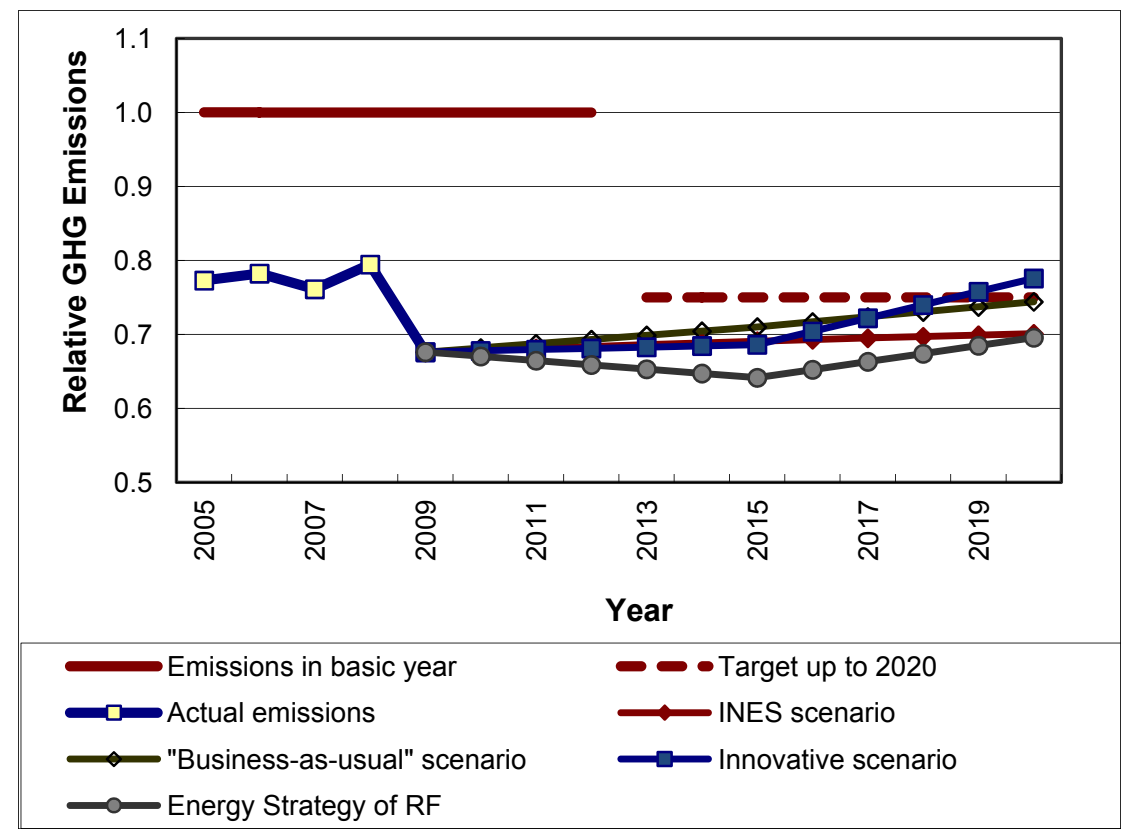

Figure 2: $\quad$ GHG emissions forecast for the Sverdlovsk Region.

energy (according to 2006 guidelines for classification) is responsible for more than $95 \%$ of the total emissions. Therefore, the consequent activity was focused on the emissions, tied in with fossil fuel consumption.

The input of different categories of sources into overall emissions is presented on the figure 3 .

Power and heat generation are responsible for about $62 \%$ of GHG emissions in the Sverdlovsk Oblast, the iron and steel industry is responsible for $14 \%$ of emissions and natural gas transportation accounts for $7 \%$. So these sectors might hold the main potential for GHG emission reduction, taking into account that $90 \%$ of electricity and heat is produced by incinerating fossil fuel.

The next step was the analysis of power and heat generation, transmission and consumption structure and efficiency. For instance, the heating of buildings (residential, industrial, office, trading, etc.) consumes $90 \%$ of heat and only $10 \%$ of heat goes towards industrial needs according to the Tacis report [2]. The specific heat consumption of the buildings constructed before 2004 exceeds the modern standards by $5-20 \%$.

A second example is as follows: despite the fact that fuel use per $\mathrm{kWh}$ has started to reduce since 2009, in average it is still far from the best available technologies, such as Combined Heat and Power (CHP).

Based on an in-depth study the list of specific technical measures (including their input into overall GHG emission reduction) was developed as a part of the local low-carbon strategy. All the technical measures are combined into four clusters (see Table 1). 


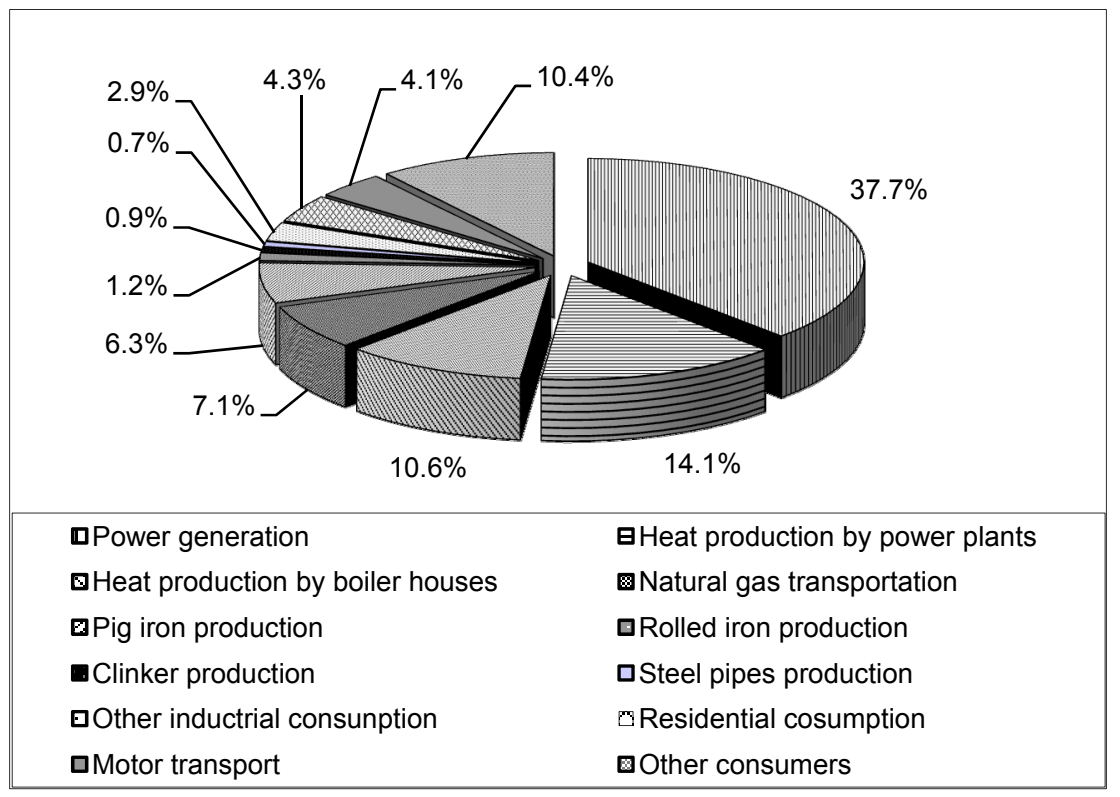

Figure 3: $\quad$ Fuel consumption breakdown in Sverdlovsk Oblast.

Table 1: The potential for GHG emission reduction in the Sverdlovsk Region (relative to the current emissions) as of 2009.

\begin{tabular}{|l|c|c|}
\hline \multicolumn{1}{|c|}{ Cluster } & Potential & $\begin{array}{c}\text { Share of cluster in } \\
\text { total potential }\end{array}$ \\
\hline $\begin{array}{l}\text { Energy efficiency at the end users } \\
\text { side }\end{array}$ & $24.90 \%$ & $66.40 \%$ \\
\hline Renewable energy & $2.80 \%$ & $7.47 \%$ \\
\hline $\begin{array}{l}\text { Heat and power generation } \\
\text { efficiency }\end{array}$ & $9.00 \%$ & $24.00 \%$ \\
\hline Power and heat distribution & $0.80 \%$ & $2.13 \%$ \\
\hline Total & $\mathbf{3 7 . 5 0 \%}$ & $\mathbf{1 0 0 . 0 0 \%}$ \\
\hline
\end{tabular}

Cluster heat and power generation efficiency includes the partial power generation decentralization and wider use of the CHP instead of local boiler houses.

The estimates take into account the interdependence of the potential for different clusters. For instance, the reduction of demand will result in energy generation decline, which in turn reduces the potential for total GHG emission reduction on the generation side. 
A significant input into the low-carbon strategy was made by V. G. Lisienko and other authors [3, 4]. They have developed specific emission factors for different metallurgical processes such as the iron ore and sinter production, the Siemens-Martin process, BOF, the electric arc melting process and others. This allows for calculating the full carbon footprint of metal products.

Another part of the low-carbon strategy is devoted to institutional issues. The important part of low-carbon growth is the optimization of contractual relations between heat suppliers and end users. This will help to reduce the oversupply, heat generation and GHG emissions.

\section{Barriers and possible solutions}

Unfortunately the potential for the curb of GHG emission is currently being realized too slowly. The following reasons are responsible for this:

a) The lack of a methodological basis in Russia, which allows GHG emissions assessment through the whole life-cycle of products, services, projects (Scope 1, Scope 2 and Scope 3 emissions). To eliminate this barrier the authors have calculated the $\mathrm{CO}_{2}$ emissions for a number of separate processes and products. Calculations are based on the regional statistical data. But to assess the full carbon footprint, a life cycle analysis for each product is required.

b) Weak institutional basis, lack of the carbon emission regulation. The edict of the president of the Russian Federation is not supported by any specific regulation.

c) Conflict of interests among stakeholders. Most of the parties have low incentives for energy efficiency rise. Energy efficiency results in falling incomes of heat and power generators and suppliers. Generators and suppliers try (often successfully) to compensate the shortfall in income by raising tariffs. That leads to an extension of the pay-back period for investments made by the end users into the energy efficiency and reduces the investments efficiency.

Detailed analysis shows that implementation in Russia of carbon cup-and-trade system might bring additional incentives for energy conservation. But this system should meet the following conditions.

- The carbon tax shouldn't be included into the primary cost of the energy. It should be paid from the profit. Or else the tax burden will be transferred to the end user and incentive will disappear for carbon emitters.

- Energy conservation will result in energy demand reduction. The gain from carbon emission reduction should be higher than the falling income of generators. This provision stipulates the minimal carbon cost.

- The profit tax forms the significant part of the regional budget. Energy conservation will lead to the generators profit decline and reduction of the regional budget. So the carbon tax has to be split between federal and regional level in the proportion which cover the regional budget shortage from energy conservation. 
Table 2: $\quad$ Carbon footprint for selected processes/products in Sverdlovsk Oblast.

\begin{tabular}{|c|c|c|}
\hline Process/Product & Unit & Specific $\mathrm{CO}_{2}$ \\
\hline Supplied electricity & MWh & $643 *$ \\
\hline Heat supplied by power plants & Gcal & 343 \\
\hline Heat supplied by boiler houses & Gcal & 370 \\
\hline Losses in district heating grid & Gcal & 20 \\
\hline Pig iron production & metric ton & 1212.6 \\
\hline Martin steel & metric ton & 862.5 \\
\hline BOF steel & metric ton & 20.0 \\
\hline Electric steel & metric ton & 31.3 \\
\hline Rolled iron & metric ton & 172.3 \\
\hline Steel pipes & metric ton & 357.6 \\
\hline Oxygen & thous. $\mathrm{m}^{3}$ & 281 \\
\hline Compressed air & thous. $\mathrm{m}^{3}$ & 89 \\
\hline Timber harvesting & $\mathrm{m}^{3}$ & 5 \\
\hline Commercial timber & thous. $\mathrm{m}^{3}$ & 3169 \\
\hline Lumber & thous. $\mathrm{m}^{3}$ & 39545 \\
\hline Plywood & $\mathrm{m}^{3}$ & 590 \\
\hline Wallboard & thous. $\mathrm{m}^{2}$ & 2570 \\
\hline Wood chipboard & thous. $\mathrm{m}^{3}$ & 265 \\
\hline Cement & metric ton & 78 \\
\hline Clinker & metric ton & 390 \\
\hline Ceramic tiles & thous. $\mathrm{m}^{2}$ & 7828 \\
\hline Bricks & thous. pieces & 572 \\
\hline Panel board & thous. $\mathrm{m}^{2}$ & 295975 \\
\hline Iron concrete items & thous. $\mathrm{m}^{3}$ & 209882 \\
\hline Soft roofing material & thous. $\mathrm{m}^{2}$ & 7317 \\
\hline Water use, total & thous. $\mathrm{m}^{3}$ & 916 \\
\hline $\begin{array}{l}\text { Including: } \\
\text { Water supply }\end{array}$ & thous. $\mathrm{m}^{3}$ & 334 \\
\hline Sewage water treatment & thous. $\mathrm{m}^{3}$ & 336 \\
\hline Water pumping & thous. $\mathrm{m}^{3}$ & 245 \\
\hline
\end{tabular}

* Source: Tacis report [5] 


\section{Conclusions}

The following conclusions can be made as a result of this work:

a) The targets for the curb of GHG emission by 2020 set by the edict of the president of the Russian Federation are achievable, in particular, in the Sverdlovsk Region.

b) The draft for the low-carbon local strategy of Sverdlovsk Oblast is developed.

c) Additional energy efficiency measures are required to slow down the GHG emission growth.

d) The potential for GHG cutting is about $37.5 \%$ of the current rate.

e) The main directions of the GHG emission curb activity are the energy efficiency at the user side and during heat and power generation.

f) There are a number of barriers for low-carbon strategy implementation, including low incentives for heat and power generators and distributors, weak GHG regulation at the state level and the lack of methodological basis.

g) The introduction of the GHG cap-and-trade scheme may bring incentives but this scheme should meet certain requirements.

\section{References}

[1] Anufriev, V.P., Galenovich, A.Yu., Kuligin, A.P. \& Starodubets, N.V. Regional low-carbon strategy at an example of Sverdlovsk oblast. Ural State Federal University: Yekaterinburg. 2012. p 135.

[2] The integrated fuel and energy balances of Rostov, Tver' and Sverdlovsk regions. Report on Project "Promoting investments in energy savings projects in Russian Federation regions". The European Union's Tacis programme for the Russian Federation. EuropeAid/126554/C/SER/RURU. February 2009.

[3] Chesnokov, Yu.N., Lisienko, V.G. \& Lapteva, A.V. Development of graphs for carbon dioxide emission by steel companies. Metallurg: Moscow, No12, 2012, pp. 23-26.

[4] Anufriev, V.P., Lisienko, V.G., Kuligin, A.P., et.al. Analysis of possibility for reduction of fuel consumption and carbon dioxide emissions as well as for carbon investments by an example of enterprises of Sverdlovsk region. Metallurg: Moscow, No 4, 2013, pp. 24-29.

[5] The emission factors development for power systems of three regions. Auxiliary document. Report on Project "Promoting investments in energy savings projects in Russian Federation regions". The European Union's Tacis programme for the Russian Federation. EuropeAid/126554/ C/SER/RURU. April 2009. 